\title{
Correction to: Intercultural Dynamics of First Acquaintance: Comparative Study of Swedish, Chinese and Swedish-Chinese First Time Encounters
}

Jens Allwood, Nataliya Berbyuk Lindström, and Jia Lu

\begin{abstract}
Correction to:
Chapter "Intercultural Dynamics of First Acquaintance:

Comparative Study of Swedish, Chinese and Swedish-Chinese

First Time Encounters" in: C. Stephanidis (Ed.):

Universal Access in Human-Computer Interaction, LNCS 6768, https://doi.org/10.1007/978-3-642-21657-2_2
\end{abstract}

In an older version of this paper, there was an orthographical error in the title. The letter "r" was missing from the word "First". This has been corrected. 